Arkan S Sayed-Noor, Sebastian Mukka, Maziar Mohaddes, Johan Kärrholm, Ola Rolfson. Sweden: Acta Orthop, 2019 Jun, Vol. 90(3), pp. 220-225. 30931664.

7. Population-Based Rates of Revision of Primary Total Hip Arthroplasty: A Systematic Review. Kelly L. Corbett, Elena Losina, Akosua A. Nti, Julian J. Z. Prokopetz, Jeffrey N. Katz. Massachusetts, USA: PLoS One, 2010 Oct, Vol. 5(10), p. e13520. 20976011.

8. What Is the Risk of Revision Surgery in Hydroxyapatite-coated Femoral Hip Stems?
Findings From a Large National Registry. Maria C Inacio, Michelle Lorimer, David C Davidson, Richard N De Steiger, Peter L Lewis, Stephen E Graves. s.I: Clin Orthop Relat Res, 2018 Dec, Vol. 476(12), pp. 2353-2366. 30303878.

9. The Effect of Size for a Hydroxyapatite-Coated Cementless Implant on Component Revision in Total Hip Arthroplasty: An Analysis of 41,265 Stems. Wayne T Hoskins, Roger J Bingham, Michelle Lorimer, Richard N de Steiger. s.l: ] Arthroplasty, 2020 Apr, Vol. 35(4), pp. 1074-1078. 31787355.

\title{
ĐÁNH GIÁ KẾT QUẢ TẠO HÌNH KHUYẾT HỔNG KHOANG MIỆNG BẰNG VẠT DƯớI CẰM TRONG ĐIỀU TRI PHẪU THUẬT UNG THƯ KHOANG MIỆNG
}

\author{
Lê Văn Quảng ${ }^{1,2}$, Ngô Quốc Duy ${ }^{1}$, Lê Thế Đường ${ }^{1}$, \\ Trần Đức Toàn ${ }^{1}$, Nguyễn Văn Trọng ${ }^{2}$, Ngô Xuân Quý $^{1}$
}

TÓM TẮT

Mục tiêu: Đánh giá kết quả tạo hình khuyết hổng khoang miệng bằng vạt dưới cằm trong điều trị phẫu thuật ung thư khoang miệng. Đối tượng nghiên cứu: Bao gồm $25 \mathrm{BN}$ mắc ung thư khoang miêng được phẫu thuật cắt bỏ u và tạo hình bằng vat dưới cằm tai khoa Ngoai đâu cổ, Bênh viên $\mathrm{K}$ giai đoaan từ T1/2015 đến T3/2020. Phương pháp nghiên cứu: Mô tả hồi cứu kêtt hợp tiến cứu. Kết quả: Trong số 25 BN nghiên cứu, tuổi mắc bệnh trung bình là $56,4 \pm$ 10,3 tuổi; Tỷ lế Nam/ Nữ 7,3/1. Trong đó: 17 BN ung thư sàn miệng, 4 BN niêm mạc má, 3 BN lưỡi, 1 BN lợi hàm dưới; BN chủ yếu ở giai đoan T2 $(64 \%)$ và No (72\%). Kích thước u trung bình $22,4 \pm 6,2 \mathrm{~mm}$. Kích thước vat dưới cằm, chiêu dài trung bình $42,8 \pm$ $7,9 \mathrm{~mm}$, chiều rộng trung bình $30,2 \pm 6,8 \mathrm{~mm}$. Tình trang vat tao hình sau mổ $88 \%$ sống, có 3 TH vat hoai tử một phần chiếm $12 \%$. Chức năng phát âm và nuốt sau mổ đều đat kết quả tốt và trung bình ở tất cả các bênh nhân. Có $68 \%$ được xa trị hoăc hóa xa trị sau mổ, không có mối liên quan giữa điêu trị tia xạ sau mổ với tỷ lê vat sống $(p=0,527)$, chức năng nói $(p=$ $0,114)$ và chức năng nuốt $(p=0,432)$. Kết luân: Vạt dưới cằm là lựa chọn thích hợp cho các khuyểt hổng trong khoang miệng kích thước từ nhỏ đến trung bình sau cắt bỏ u nguyên phát do đây là kỹ thuật an toàn, hiệu quả, tỷ lệ biến chứng thấp, kèm theo kết quả chức năng tốt, thẩm mỹ.

Từ khóa: ung thư khoang miệng, tạo hình, vạt dưới cằm.

\section{SUMMARY \\ OUTCOMES OF SUBMENTAL FLAP RECONSTRUCTION FOR ORAL DEFECTS IN}

\footnotetext{
${ }^{1}$ Bệnh viện $K$ Trung Ương

${ }^{2}$ Trường Đại hoc Y Hà Nối

Chịu trách nhiệm chính: Lê Văn Quảng

Email: Lequang@hmu.edu.vn

Ngày nhận bài: 11.11 .2020

Ngày phản biên khoa hoc: 5.01 .2021

Ngày duyệt bài: 18.01.2021
}

SURGICAL TREATMENT OF ORAL CANCER

Obiectives: To evaluate the result of OCC treatment using nasolabial flap reconstruction. Patients and methods: 25 cases of carcinoma of oral cavity who had undergone excision and reconstruction using a submental flap between January 2015 and March 2020. Results: The mean age was $56,4 \pm 10,3$. Male/Female was $7,3 / 1$. In total 25 patients, there were 17 floor of the mouth cancer patients, 4 buccal mucosa cancer patients, 3 tongue cancer patients, and 1 lower gingiva cancer patient. The mean tumor size was $31,2 \pm 8,0 \mathrm{~mm}$. The mean length of flap was $42,8 \pm 7,9 \mathrm{~mm}$, and the mean width was $30,2 \pm 6,8 \mathrm{~mm}$. Flap survival was $88 \%$ and partial necrosis occurred in 3 patients $(12 \%)$. The postoperative speech and swallowing function were good and intermediate level. Conclusion: Submental flap is simple and viable option in the reconstruction of small to medium oral defects after excision of oral cancer with good functional outcome and minimal complications.

Key words: oral cavity cancer, reconstruction, submental flaps.

\section{I. ĐẶT VẤN ĐỀ}

Ung thư khoang miệng là một trong những bênh lý ung thư phổ biến, chiếm tới $30-40 \%$ ung thư vùng đầu cổ. Phẫu thuật là phương pháp điều trị chính, với nguyên tắc phẫu thuật cắt u rộng rãi, nạo vét hạch hệ thống kết hợp với phẫu thuật tao hình lại khuyết hổng[1]. Viêcc phuc hồi các khiếm khuyết vùng miệng sau khi phẩu thuật cắt bỏ $u$ cần đảm bảo cả về hình thái và chức năng. Vạt dưới cằm được mô tả lần đầu năm 1993 bởi Martin và ngày càng được sử dụng rộng rãi với nhiều ưu điểm: hình thái, màu sắc và tổ chức đồng điệu với mô cắt, vạt dài (có thể dài tới $8 \mathrm{~cm}$ ), cuống chắc sức sống tốt, seo nơi tao vat đước che bởi bờ dưới cằm [2]. Ngoài ra, nhiêu nghiển cứu cho thấy vạt dưới cằm an toàn và hiệu quả khi tạo hình cho nhóm bệnh nhân 
ung thư khoang miệng [3], [4], [5].

Tại Việt Nam hiện chưa có nhiều báo cáo về an toàn và hiệu quả trong sử dụng kỹ thuật tạo hình vạt dưới cằm trong tái tạo các khuyết hổng sau phẫu thuật ung thư khoang miệng. Do đó, chúng tôi tiến hành nghiên cứu này với mục tiêu: Đánh giá kết quả tạo hình bằng vat dưới cằm trong phẫu thuật ung thư khoang miệng.

\section{II. ĐỐI TƯỢNG VÀ PHƯƠNG PHÁP NGHIÊN CỨU}

2.1. Đối tượng nghiên cứu. Bao gồm 25 bệnh nhân mắc ung thư khoang miệng được phẫu thuật cắt rộng u và tạo hình bằng vạt dưới cằm tại khoa Ngoại đầu cổ, Bệnh viện $\mathrm{K}$ giai đoạn từ $T 1 / 2015$ đến $T 3 / 2020$.

\subsection{Phương pháp nghiên cứu}

2.2.1. Thiết kế nghiên cứu: Mô tả hồi cứu kết hợp tiến cứu

\subsubsection{Phương pháp thu thập số liệu}

Thu thập số liệu, thông tin bệnh nhần theo một mẫu bệnh án nghiên cứu thống nhất.

- Tuổi, giới, thời gian phát hiện bệnh (tháng), triệu chứng lâm sàng, tiền sử, vị trí, kích thước khối u, giai đoạn bệnh TNM (theo phân loại AJCC 2017), điều trị bổ trợ trước.

- Thông tin ghi nhân trong mổ: vị trí, kích thước khuyết hổng, kích thước vạt, thời gian lấy vạt, mức độ vét hạch cổ, tai biến trong mổ.

- Kết quả sớm sau mổ: biến chứng sau mổ, tình trạng vạt, vị trí lấy vạt

- Đánh giá phục hồi chức năng (chức năng nói, ăn, nuốt), thẩm mỹ sau mổ, theo dõi tái phát, sống thêm toàn bộ.
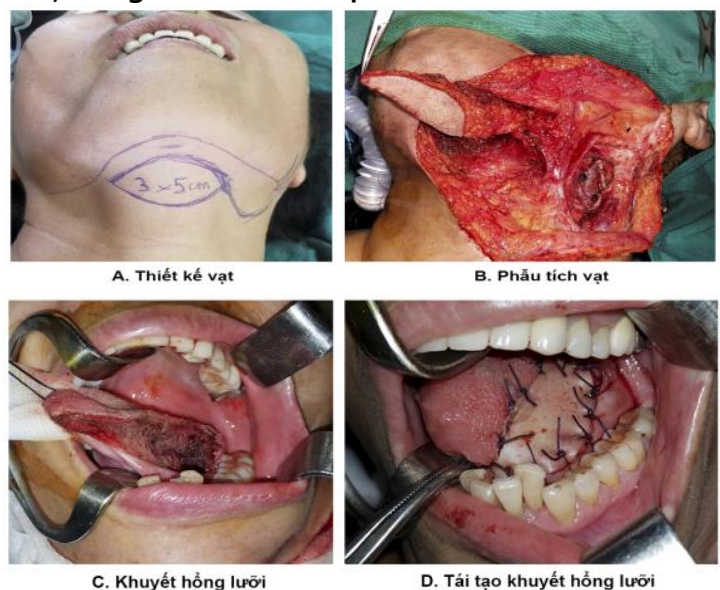

III. KẾT QUẢ NGHIÊN CỨU

\section{1. Đăc điểm bênh nhân}

Bảng 1. Đặc điểm bệnh nhân

\begin{tabular}{|c|c|c|}
\hline Tuổi & $\mathbf{5 6 , 4} \pm \mathbf{1 0 , 3}$ & $\mathbf{3 5 - 7 5}$ \\
\hline Giới (Nam/Nư) & $22 / 3$ & $88,0 \% / 12,0 \%$ \\
\hline
\end{tabular}

\begin{tabular}{|c|c|c|}
\hline Kích thước u & $22,4 \pm 6,2 \mathrm{~mm}$ & $15-35 \mathrm{~mm}$ \\
\hline \multicolumn{3}{|c|}{ Vị trí u } \\
\hline Đặc điếm & $\mathbf{N}$ & $\%$ \\
\hline Sàn miệng & 17 & $68 \%$ \\
\hline Niêm mạc má & 4 & $16 \%$ \\
\hline Lưỡi & 3 & $12 \%$ \\
\hline Lợi hàm & 1 & $4 \%$ \\
\hline \multicolumn{3}{|c|}{ Gíai đoạn pT } \\
\hline T1 & 4 & $16 \%$ \\
\hline $\mathrm{T} 2$ & 16 & $64 \%$ \\
\hline T3 & 5 & $20 \%$ \\
\hline \multicolumn{3}{|c|}{ Gíai đoạn pN } \\
\hline No & 18 & $72 \%$ \\
\hline N1 & 2 & $8 \%$ \\
\hline N2a & 0 & $0 \%$ \\
\hline N2b & 5 & $20 \%$ \\
\hline \multicolumn{3}{|c|}{$\begin{array}{l}\text { Phương pháp phâu thuật } \\
\end{array}$} \\
\hline $\begin{array}{l}\text { Cắt rộng u, tạo } \\
\text { hình, VHC } 1 \text { bên }\end{array}$ & 19 & $76 \%$ \\
\hline $\begin{array}{l}\text { Cắt rộng u, tạo } \\
\text { hình, VHC } 2 \text { bên }\end{array}$ & 4 & $16 \%$ \\
\hline $\begin{array}{l}\text { Cắt rộng u, cắt } \\
\text { xương hàm dưới } \\
\text { không đứt đoạn, } \\
\text { tạo hình, VHC }\end{array}$ & 2 & $8 \%$ \\
\hline
\end{tabular}

Nhận xét: Tuối mắc bệnh lớn nhất là 75 , nhỏ nhất là 35 , tuổi trung bình là $56,4 \pm 10,3$. Tỷ lệ nam/nữ là $7,3 / 1$. Thường gặp nhất là u sàn miệng chiếm $68 \%$, vị trí lợi hàm ít gặp, không có $\mathrm{BN}$ nào ung thư vị trí khẩu cái. U thường gặp nhất ở giai đoạn T2 (64\% trường hợp), 72\% trường hợp chưa có di căn hạch vùng No.

\section{2. Đặc điểm phẫu thuật}

Bảng 2. Đặc điểm phấu thuật Kích thước vat trung bình

\begin{tabular}{|l|l|l|} 
Chiêu dài & $42,8 \pm 7,9 \mathrm{~mm}$ & $30-60 \mathrm{~mm}$ \\
\hline
\end{tabular}

\begin{tabular}{l|l|l} 
Chiều rộng & $30,2 \pm 6,8 \mathrm{~mm}$ & $20-40 \mathrm{~mm}$ \\
\hline
\end{tabular} Thời gian bóc vạt trung bình

\begin{tabular}{c|c|c|}
$\begin{array}{c}\text { Thời gian } \\
\text { bóc vat }\end{array}$ & $\begin{array}{c}50,6 \pm 11,5 \\
\text { phút }\end{array}$ & $40-70$ phút
\end{tabular}

Nhân xét: Vat dưới cằm lấy được có kích thước vừa và nhỏ, từ $30-60 \mathrm{~mm}$. Thời gian bóc vạt trung bình là $50,6 \pm 11,5$ phút.

2.3. Kết quả sớm sau mổ

Bảng 3: Kết quả sớm sau mổ

\begin{tabular}{|c|c|c|}
\hline Đặc điểm & $\mathbf{N}$ & $\mathbf{\%}$ \\
\hline \multicolumn{2}{|c|}{ Tình trạng vạt tạo hình } \\
\hline Sống & 22 & $88 \%$ \\
\hline Hoại tử 1 phần & 3 & $12 \%$ \\
\hline Hoạt tử toàn bộ & 0 & $0 \%$ \\
\hline \multicolumn{2}{|c|}{ Thời gian nằm viện trung bình } \\
\hline $\begin{array}{c}\text { Thời gian nằm } \\
\text { viện }\end{array}$ & $\begin{array}{c}10,5 \pm 2,0 \\
\text { ngày }\end{array}$ & $\begin{array}{c}8-12 \\
\text { ngày }\end{array}$ \\
\hline
\end{tabular}


Nhân xét: $88 \%$ vạt tạo hình sống, 3 BN hoại tử 1 phần vạt chiếm $12 \%$, không có $B N$ hoại tử toàn bộ vạt. Thời gian nằm viện trung bình là $10,5 \pm 2,0$ ngày.

2.4. Đánh giá phục hồi chức năng, thẩm mỹ sau phẫu thuật

Bảng 4: Đánh giá chức năng và thẩm mỹ sau mố

\begin{tabular}{|c|c|c|}
\hline Đăc điếm & $\mathbf{N}$ & $\%$ \\
\hline \multicolumn{3}{|c|}{ Chức năng nói } \\
\hline Nói khó & 0 & $0 \%$ \\
\hline $\begin{array}{l}\text { Nói được (chi người } \\
\text { nhà nghe hiểu) }\end{array}$ & 0 & $0 \%$ \\
\hline $\begin{array}{c}\text { Nói được (người ngoài } \\
\text { nghe hiểu) }\end{array}$ & 12 & $48 \%$ \\
\hline Nói bình thường & 13 & $52 \%$ \\
\hline $\begin{array}{l}\text { Thời gian hồi phục } \\
\text { trung bình }\end{array}$ & $\begin{array}{l}3,8 \pm 1,6 \\
\text { tuần }\end{array}$ & $\begin{array}{l}2-8 \\
\text { tuần }\end{array}$ \\
\hline \multicolumn{3}{|c|}{ Chức năng ăn, nuốt } \\
\hline Không ăn được & 0 & $0 \%$ \\
\hline Ân được thức ăn lỏng & 0 & $0 \%$ \\
\hline An được thức ăn đăc & 9 & $36 \%$ \\
\hline Ān được cơm & 16 & $64 \%$ \\
\hline $\begin{array}{l}\text { Thời gian hồi phục } \\
\text { trung bình }\end{array}$ & $\begin{array}{l}\text { 4,9 } \pm 1,8 \\
\text { tuần }\end{array}$ & $\begin{array}{l}2-8 \\
\text { tuần }\end{array}$ \\
\hline
\end{tabular}

\begin{tabular}{|c|c|c|}
\hline \multicolumn{3}{|c|}{ Tính thấm mỹ vùng mặt } \\
\hline Biến dạng & 0 & 0 \\
\hline Méo miệng & 1 & $4 \%$ \\
\hline Bình thường & 24 & $96 \%$ \\
\hline
\end{tabular}

Nhân xét: $100 \%$ BN nói được trong đó 52\% BN nói bình thường với thời gian phục hồi trung bình là 3,8 $\pm 1,6$ tuần. $100 \%$ BN ăn nuốt được, trong đó $64 \%$ BN ăn được cơm, thời gian phục hồi trung bình $4,9 \pm 1,8$ tuần. Vạt dưới cằm cho kết quả tốt về thẩm mỹ, không có $B N$ nào biến dạng mặt. Có 1 BN méo miệng (chiếm 4\% trường hợp) do tổn thương thần kinh bờ hàm dưới trong quá trình phẫu thuật.

\section{5. Điêuu trị bổ trợ sau phẫu thuật}

Bảng 5: Điều trị sau phẫu thuật

\begin{tabular}{|c|c|c|}
\hline Điều trị bố trợ & $\mathbf{N}$ & $\mathbf{\%}$ \\
\hline Không & 8 & $32 \%$ \\
\hline Xạ trị bố trợ & 12 & $48 \%$ \\
\hline Hóa xạ trị bố trợ & 5 & $20 \%$ \\
\hline
\end{tabular}

Nhận xét: Đa số bệnh nhân sau phẫu thuật được điều trị bổ trợ, có $32 \%$ BN sau phẫu thuật chỉ ra viên theo dõi.

- Mối liên quan giữa xạ trị và tình trạng vạt, phục hồi chức năng

Bảng 6: Môi liên quan xạ trị và kêt quả vạt, chức năng nói, nuốt

\begin{tabular}{|c|c|c|c|c|c|}
\hline & \multicolumn{2}{|c|}{ Xạ trị } & \multirow{2}{*}{$\begin{array}{l}\text { Tổng số } \\
\text { N (tî̉ lệ) }\end{array}$} & \multirow[b]{2}{*}{$\mathbf{p}$} \\
\hline & & $\begin{array}{c}\text { Có } \\
\mathbf{N} \text { (tỉ lệ) }\end{array}$ & $\begin{array}{c}\text { Không } \\
\text { N (tî lệ) }\end{array}$ & & \\
\hline \multirow{2}{*}{ Kết quả vạt } & Sống & $8(32 \%)$ & $14(56 \%)$ & $22(88 \%)$ & \multirow{2}{*}{0,527} \\
\hline & Hoại tử 1 phần & $0(0 \%)$ & $3(12 \%)$ & $3(12 \%)$ & \\
\hline \multirow{2}{*}{$\begin{array}{l}\text { Chức năng } \\
\text { nói }\end{array}$} & Nói được (người ngoài nghe hiếu) & $2(8 \%)$ & $10(40 \%)$ & $12(48 \%)$ & \multirow{2}{*}{0,114} \\
\hline & Nói bình thường & $6(24 \%)$ & $7(28 \%)$ & $13(52 \%)$ & \\
\hline $\begin{array}{c}\text { Chức năng } \\
\text { nuốt }\end{array}$ & $\begin{array}{l}\text { Àn được thức ăn đặc } \\
\text { Án đước cơm }\end{array}$ & $\begin{array}{c}2(8 \%) \\
6(24 \%)\end{array}$ & $\begin{array}{c}7(28 \%) \\
10(40 \%)\end{array}$ & $\begin{array}{c}9(36 \%) \\
16(64 \%)\end{array}$ & \multirow[t]{2}{*}{0,432} \\
\hline & Tống số & $8(32 \%)$ & $17(68 \%)$ & $25(100 \%)$ & \\
\hline
\end{tabular}

Nhận xét: Không có mối liên quan giữa xạ trị sau phẫu thuật với kết quả vạt, chức năng nói, chức năng nuốt (tương ứng giá trị $P$ lần lượt 0,$527 ; 0,114 ; 0,432$ ).

\section{BÀN LUÂ̂N}

Trong thời gian nghiên cứu, chúng tôi thu thập được 25 bệnh nhân phẫu thuật ung thư khoang miệng có tạo hình sứ dụng vạt dưới cằm. Trong đó, có 22 nam và 3 nữ, độ tuổi trung bình 56,4 tuổi. Các bệnh nhân trong nghiên cứu được phát hiện bệnh ở giai đoạn còn sớm, với T1-2 chiếm $80 \%$ và $N 0$ chiếm $72 \%$, kết quả này cao hơn nghiên cứu của Cariati với tỷ lệ T1-2 67\% và No $77 \%[6]$, còn trong nghiên cứu của Muhammad, tỳ lệ T1-2 63\% và N0 85\% [7].

4.1. Đặc điểm phẫu thuật. Vạt dưới cằm được mô tả lần đầu năm 1993 bởi Martin và trở thành phổ biến trong tạo hình các khuyết hổng vừa và nhỏ vùng khoang miệng với nhiều ưu thế như thời gian lấy vạt nhanh chóng nhưng đảm bảo an toàn và tính thẩm mỹ [2]. Vạt có cuống mạch từ động mạch dưới cằm, một nhánh bên lớn của động mạch mặt tách ra trước khi động mạch bắt chéo bờ hàm dưới, với khuyết hổng lấy vạt trùng với nếp da dưới cằm cho kết quả thẩm mỹ tốt.

Trong nghiên cứu của chúng tôi, kích thước vạt trung bình chiêuu dài $42,8 \pm 7,9 \mathrm{~mm}$, chiều rộng 30,2 $\pm 6,8 \mathrm{~mm}$, tương tự nghiên cứu của Sebastian với kích thước vạt trung bình $49 x$ 40mm [8], nhỏ hơn vạt lây được của Chow $51 x$ $60 \mathrm{~mm}$ [9]. Nhìn chung, vat dưới cằm linh động về kích thước phù hợp với tổn thương cắt bỏ, trong số bệnh nhân nghiên cứu, vạt được lấy có chiều dài $30-60 \mathrm{~mm}$, đảm bảo về thẩm mỹ sau cắt rộng rãi $u$ vùng khoang miệng. Trong nghiên 
cứu của Chow, vạt lớn nhất lấy được có chiều dài $12 \mathrm{~cm}$ tạo hình sau cắt bỏ ung thư má và không có hoại tử vạt sau đó.

Mặc dù kích thước vạt vừa và nhỏ, nhưng cũng đủ che phủ được các trường hợp khuyết hổng có cắt không đứt đoạn xương hàm dưới. Như trong nghiên cứu này, vạt dưới cằm sử dụng tốt và đảm bảo trong 2 trường hợp phẫu thuật cắt u sàn miệng kèm cắt không đứt đoạn xương hàm dưới. Muhammad cũng sử dụng vạt dưới cằm tạo hình 8 trường hợp có cắt $u$ kèm đoạn xương hàm, các vạt đều không bị hoại tử và đảm bảo chức năng nói và nuốt [7].

4.2. Kết quả sớm sau mổ. Chúng tôi phân tích trạng thái của vạt dựa trên hiện tượng vạt sống, hoại tử hoàn toàn hay hoại tử một phân. Mă̆t khác, kết quả trạng thái của vạt cũng trùng với kết quả mức độ nhận máu của vạt và đánh giá về mặt phẫu thuật. Vì vậy, chúng tôi lấy kết quả này làm đại diện để so sánh với các nghiên cứu khác.

Trong nghiên cứu của chúng tôi, $88 \%$ vạt tạo hình sống, 3 bệnh nhân hoại tử 1 phần vạt chiếm $12 \%$ và không có trường hợp nào hoại tử vạt toàn bộ. Tỷ lệ vạt sống trong nghiên cứu của chúng tôi cao hơn Muhammad với $85 \%$ (trong khi $15 \%$ vat hoạ tử một phần) [7] và cao hơn Sittitrai với $71 \%$ (trong khi 29\% hoại tử 1 phần) [3], thấp hơn Chow với 93,3\% (trong khi 6,7\% vạt hoại tử 1 phần)[9], còn trong nghiên cứu của Zenga với 24 bệnh nhân, không có trường hợp hoại tử vạt nào. Thời gian nằm viện sau mổ trung bình 10,5 ngày, tương ứng với thời gian vạt hồi phục và rút sonde dạ dày, không có bệnh nhân nào nằm hậu phẫu quá 2 tuần.

4.3. Đánh giá phục hôi chức năng, thẩm mỹ sau phẫu thuật. Trong phẫu thuật ung thư sàn miệng, mục tiểu lý tưởng là phẫu thuật cắt bỏ u rộng rãi, nhưng cần đảm bảo về tính thẩm mỹ và chức năng sau mổ. Bảo tồn chức năng nói và nuốt là cần thiết để đảm bảo chất lượng cuộc sống sau này của bệnh nhân. Trong nghiên cứu của chúng tội, tất cả các bệnh nhân đều nói được sau phẫu thuật, trong đó $52 \%$ bệnh nhân nói bình thường, với thời gian phục hồi trung bình $4,9 \pm 1,8$ tuần, kết quả này tương tự như nghiên cứu của Cariati và Chow với tất cả bệnh nhân đều có thể nói hiểu được [6],[9].

Tất cả các bệnh nhân ăn nuốt được, trong đó $64 \%$ bệnh nhân ăn được cớm bình thường và không có trường hợp nào cần đặt sonde dạ dày nuôi ăn thay thế, kết quả này tương tự nghiên cứu của Chow với $66 \%$ số bệnh nhân ăn uống bình thường và 1 trường hợp cần đặt sonde dạ dày nuôi dưỡng do hoại tử vạt gây rò mũi miệng [9].

Trong nghiên cứu của chúng tôi, không có trường hợp nào biến dạng mặt sau phẫu thuật. Một trường hợp méo miệng do tổn thương thần kinh bờ hàm dưới trong quá trình phẫu thuật.

4.4. Điều trị bổ trợ sau phẫu thuật. Trong nghiên cứu của chúng tôi, $68 \%$ bệnh nhân được điêu trị bổ trợ sau phẫu thuật, với xạ trị hoặc hoá xạ trị. Tuy nhiên, không có mối liên quan giữa điều trị tia xạ với tỷ lệ vạt sống $(p=0,527)$, chức năng nói $(p=0,114)$ và chức năng nuốt $(p$ $=0,432$ ).

\section{KẾT LUÂ̂N}

- Vạt dưới cằm lấy được có kích thước vừa và nhỏ, trung bình $42,8 \times 30,2 \mathrm{~mm}$.

- Thời gian bóc vat trung bình 50,6 phút.

- Không có vạt nào hoại tử toàn bộ, tỷ lệ vạt sống $88 \%$.

- Tất cả bệnh nhân đều nói và nuốt được, với thời gian hồi phục nói trung bình 3,8 tuần, nuốt trung bình 4,9 tuần. Tính thẩm mỹ nhờ vạt dưới cằm cao, không có trường hợp nào biến dạng mặt sau mổ.

Như vậy, trong phẫu thuật ung thư khoang miệng, vạt dưới cằm là chất liệu an toàn, hiệu quả, tỷ lệ biến chứng thấp, đi kèm với kết quả thẩm mỹ và chức năng tốt. Đây là kỹ thuật có tỷ lệ thành công cao, đồng thời là lựa chọn phẫu thuật lý tưởng cho các khuyết hổng trong khoang miệng kích thước từ nhỏ đến trung bình.

\section{TÀI LIÊU THAM KHẢO}

1. DeVita V.T., Lawrence T.S., and Rosenberg S.A. (2015). DeVita, Hellman, and Rosenberg's cancer: Principles \&amp; practice of oncology: Tenth edition. DeVita, Hellman, and Rosenberg's Cancer: Principles \&amp; Practice of Oncology: Tenth Edition, 1-2280.

2. Martin D, Pascal J F, Baudet $J$, et al (1993).Thesubmentalislandflap: a new donor site. Anatomy and clinical applications as a free or pedicled flap. Plast Reconstr Surg;92(5):867-873.

3. Sittitrai P., Srivanitchapoom C., Reunmakkaew D., et al (2017). Submental island flap reconstruction in oral cavity cancer patients with level I lymph node metastasis. British Journal of Oral and Maxillofacial Surgery, 55(3), 251-255.

4. Howard B. E., Nagel T. H., Donald C. B., et al (2014). Oncologic safety of the submental flap for reconstruction in oral cavity malignancies. Otolaryngology--Head and Neck Surgery, 150(4), 558-562.

5. Wang J., Tan Y., Shen Y., et al (2020). Oncological safety of submental island flap for reconstruction of pathologically node-negative and node-positive T1-2 oral squamous cell carcinomarelated defects: $A$ retrospective study and comparison of outcomes. Oral Oncology, 102, 104507. 
6. Cariati P., Serrano A. C., Fernandez A. M., et al (2018). Is submental flap safe for the oncological reconstruction of the oral cavity? Journal of stomatology, oral and maxillofacial surgery, 119(4), 284-287.

7. Faisal M., Adeel M., Riaz S., et al (2018). The submental island flap in head and neck cancer. Annals of Maxillofacial Surgery, 8(2), 287.
8. Sebastian P., Thomas S., Varghese B. T., et al (2008). The submental island flap for reconstruction of intraoral defects in oral cancer patients. Oral oncology, 44(11), 1014-1018.

9. Chow T. L., Kwan W. W., Fung S. C., et al (2018). Reconstruction with submental flap for aggressive orofacial cancer-an updated series. American journal of otolaryngology, 39(6), 693-697.

\section{THỰC TRANG SỬ DƯNG THUỐC DỰ PHÒNG THUYÊN TẮC HUYÊTT KHỐI TĨNH MACH TRÊN BỀNH NHÂN PHẪU THUÂTT TẠI BỆNH VIỆN HỮU NGHI ĐA KHOA NGHỆ AN}

\section{TÓM TẮT}

Mục tiêu nghiên cứu: Đánh giá thực trạng sử dụng thuốc dự phòng thuyên tắc huyết khối tĩnh mạch trên bệnh nhẩn phẩu thuật tại bệnh viện Hữu Nghị đa khoa Nighê An. Đối tượng và phương pháp nghiên cứu: Nghiên cứu mô tả cắt ngang được tiến hành trên 131 bênh nhân phẩu thuất có chỉ định thuốc dư phòng huyết khối ở khoa ngoại Bệnh viện đa khoa Nghệ An. Kết quả: (1) Tỷ lệ bệnh nhân được dự phòng thuyên tắc huyết khối tĩnh mạch hợp lý theo phân tầng nguy cơ là rất cao $(96,95 \%) ;(2)$ Theo hướng dấn của VNHA 2016, tỷ lệ BN lựa chọn thuốc chông đông phù hợp là 93,89\%; (3) Tất cả bệnh nhân phấu thuật đều có thời điểm dùng thuốc chống đông phù hợp với khuyến cáo; (4) Thời điểm sử dụng thuốc dự phòng thuyên tắc huyết khối tĩnh mạch phù hợp có tỷ lệ cao, trong đó phẩu thuật chỉnh hình $(82,25 \%)$, phẩu thuât không chỉnh hình $(72,22 \%)$; (5) Tỷ lệ bênh nhân phẩu thuật không chỉnh hình có thời gian sử dụng thuốc chống đông phù hợp với khuyến cáo là $71,43 \%$, trong khi đó các bệnh nhân phẩu thuật chỉnh hình có tỷ lệ phù hợp về thời gian dùng thuốc thấp hơn $(43,55 \%)$. Kết luận: Tỷ lệ bệnh nhân được dự phòng thuyên tắc huyết khối tînh mạch hợp lý là rất cao $(96,95 \%)$. Tỷ lệ Bệnh nhân lựa chọn thuốc chống đông phù hợp là $93,89 \%$. Tất cả bênh nhân phẫu thuật đêu có thời điểm dùng thuốc chống đông phù hợp với khuyến cáo. Bệnh nhân phẫu thuật được chỉ định thời điêm dùng thuốc dự phòng thuyển tắc huyết khối tĩnh mạch phù hợp với tỷ lệ cao trong đó phẩu thuật chỉnh hình $(82,25 \%)$, phẩu thuật không chỉnh hình $(72,22 \%)$.

Tư khóa: huyết khối tĩnh mạch, phâuu thuật

\section{SUMMARY \\ THE CURENTSITUATION OF USING DRUGS TO PREVENT VENOUS THROMBOEMBOLISM IN SURGICAL PATIENTS AT NGHE AN GENERAL}

* Đai hoc Y khoa Vinh

Chịu trách nhiệm chính: Nguyễn Văn Tuấn

Email: tuanminh1975@gmail.com

Ngày nhận bài: 12.11.2020

Ngày phản biên khoa hoc: 31.12 .2020

Ngày duyệt bài: 14.01.2021

\section{Nguyễn Văn Tuấn*, Trần Thị Anh Tho* \\ FRIENDSHIP HOSPITAL}

Research objectives: To assess the current situation of using drugs to prevent venous thromboembolism in surgical patients at the Nghe An General Fiendship Hospital. Subjects and research methods: Descriptive cross-sectional study was conducted on 131 surgical patients who were indicated to use drugs to prevent thrombosis in the surgical department of Nghe An General Fiendship Hospital. Results: (1) The rate of prevention of reasonable venous thromboembolism was very high (96.95\%); (2) According to VNHA 2016's guidance, the percentage of patients using a suitable anticoagulant is $93.89 \%$; (3) All surgical patients have an appropriate time for taking anticoagulants; (4) There is a high proportion of appropriate timing of using drugs to prevent venous thromboembolism, including orthopedic surgery $(82.25 \%)$, nonorthopedic surgery $(72.22 \%)$; (5) The proportion of patients with non-orthopedic surgery who have used anticoagulants in accordance with the recommendation is $71.43 \%$, while the orthopedic surgery patients have time to use anticoagulants which conforms to recommendations is lower (43.55\%). Conclusion: The proportion of patients with reasonable prophylaxis against venous thromboembolism was very high (96.95\%). The proportion of patients receiving an appropriate anticoagulant is $93.89 \%$. All surgical patients have an appropriate timing of anticoagulant therapy. The right time to use drugs to prevent venous thromboembolism has a high rate

Keywords: venous thrombosis, surgery

\section{I. ĐĂT VẤN ĐỀ}

Thuyên tắc huyết khối tĩnh mạch không có triệu chứng nhưng là nguyên nhân quan trọng gây tử vong, đặc biệt là thuyên tắc phổi [1]. Trong ngoại khoa, bệnh nhân trải qua các cuộc phẫu thuật (PT), đặc biệt phẫu thuật chỉnh hình sẽ có nguy cơ phát triển thuyên tắc huyết khối tĩnh mach. Nguy cơ này gia tăng ở những bệnh nhân lớn tuổi, béo phì, bệnh ác tính, tiền sử bản thân hoặc gia đình bị thuyên tắc huyết khối tĩnh 